\title{
Mice Expressing Mutant Myosin Heavy Chains Are a Model for Familial Hypertrophic Cardiomyopathy
}

\author{
Karen L. Vikstrom, ${ }^{*}$ Stephen M. Factor, ${ }^{\dagger}$ and \\ Leslie A. Leinwand* \\ *Department of Molecular, Cellular, \& Developmental Biology, \\ University of Colorado, Boulder, Colorado, U.S.A. \\ ${ }^{\dagger}$ Department of Pathology, Albert Einstein College of Medicine, \\ Bronx, New York, U.S.A.
}

\begin{abstract}
Background: Familial hypertrophic cardiomyopathy (HCM) is an autosomal dominant disease characterized by ventricular hypertrophy, myocellular disarray, arrhythmias, and sudden death. Mutations in several contractile proteins, including cardiac myosin heavy chains, have been described in families with this disease, leading to the hypothesis that HCM is a disease of the sarcomere. Materials and Methods: A mutation in the myosin heavy chain (Myh) predicted to interfere strongly with myosin's binding to actin was designed and used to create an animal model for HCM. Five independent lines of transgenic mice were produced with cardiac-specific expression of the mutant Myh.

Results: Although the mutant Myh represents a small proportion $(1-12 \%)$ of the heart's myosin, the mice exhibit the cardiac histopathology seen in HCM patients.
\end{abstract}

Histopathology is absent from the atria and primarily restricted to the left ventricle. The line exhibiting the highest level of mutant Myh expression demonstrates ventricular hypertrophy by 12 weeks of age, but the further course of the disease is strongly affected by the sex of the animal. Hypertrophy increases with age in female animals while the hearts of male show severe dilation by 8 months of age, in the absence of increased mass.

Conclusions: The low levels of the transgene protein in the presence of the phenotypic features of HCM suggest that the mutant protein acts as a dominant negative. In addition, the distinct phenotypes developed by aging male or female transgenic mice suggest that extragenic factors strongly influence the development of the disease phenotype.

\section{INTRODUCTION}

Familial hypertrophic cardiomyopathy (HCM) is a clinically heterogeneous heart disease with a dominant mode of inheritance (1). The potential for understanding the pathogenesis of HCM advanced with the identification of mutations in the $\beta$ myosin heavy chain (Myh) gene in two kindreds with HCM $(2,3)$. Since then $40 \beta$ Myh mutations, primarily in the "motor" domain of the molecule, have been reported (4). The identification of mutations in additional muscle structural proteins (cardiac troponin T, $\alpha$-tropo-

Address correspondence and reprint requests to: Leslie A. Leinwand, University of Colorado, Department of Molecular, Cellular, \& Developmental Biology, Boulder, CO 80309-0347, U.S.A. myosin and cardiac myosin binding protein $\mathrm{C}$; [5-8]) has shown that HCM is also genetically heterogeneous and led to the hypothesis that HCM is a disease of the sarcomere (5). Although the genetic evidence for contractile protein defects in HCM is unequivocal, the link between these mutations and the clinical phenotype remains unclear. The dominant mode of inheritance may imply that the mutant protein acts as a dominant negative, interfering with the function of the wild-type protein. Several lines of evidence support this hypothesis. Myosin purified from HCM patients (which is a mixture of wild-type and mutant protein) exhibits decreased motility in in vitro motility assays (9). Biochemical analysis of a mutant allele (Arg403Gln) demonstrates a defect in actin-acti- 
vated ATPase activity and decreased motility in an in vitro assay (10). In addition, the mutant Myh exhibits a dominant effect when mixed with wild-type protein, disproportionately slowing the velocity of the mixture (10).

It remains to be established whether HCM mutations exhibit a dominant negative mode of action in vivo. In addition, the often dissimilar clinical phenotypes exhibited by affected members of the same family (11) or different families with identical myosin mutations (12) suggest that other factors contribute to the clinical course of the disease. Since addressing these questions in a patient population is difficult, such studies would benefit from an experimental animal model. Feline, canine, and porcine hypertrophic cardiomyopathy have been described $(13,14)$. However, a dominant inheritance pattern has not been demonstrated in these species, and the molecular defect has not been described, raising the possibility of a different molecular basis for HCM in these animals. Recently, a mouse model of HCM has been described which mimics several aspects of HCM in humans, namely the appearance of myocellular disarray, fibrosis, and cardiac dysfunction (15). However, these animals also exhibit left atrial enlargement in the absence of ventricular hypertrophy, features not typically seen in the human condition. Consequently, these animals may not prove to be suitable for studying many aspects of HCM pathogenesis, necessitating other animal models of HCM. Toward this end, we have created transgenic mouse lines which phenotypically are virtually identical to human HCM and allow the impact of contractile protein mutations on the heart to be analyzed and factors contributing to the disease's natural history to be determined.

\section{MATERIALS AND METHODS}

\section{Production of Transgenic Mice}

Transgenes were construct using standard cloning techniques. The transgene coding region consists of a rat $\alpha$ Myh cDNA (16) containing two mutations: a point mutation, G1445A, resulting in Arg403Gln and a deletion of amino acids 468527 bridged by the addition of 9 nonmyosin amino acids (SerSerLeuProHisLeuLysLeu). The coding region was flanked by a hybrid intron derived from the mammalian expression construct pMT2 1 at the $5^{\prime}$ end (Genetics Institute, Cambridge MA) and the SV40 small $t$ intron at the $3^{\prime}$ end. Transgene expression was driven by approximately $3.3 \mathrm{~kb}$ of rat $\alpha$ Myh $5^{\prime}$-flanking DNA (generously provided by B. Markham, Medical College of Wisconsin), and polyadenylation sequences were provided by SV40 small $t$ DNA. Transgene sequences were excised from the prokaryotic vector sequences, purified on agarose gels, and then injected into the pronuclei of fertilized mouse eggs from CBA/B 16 (Fl cross) mice according to standard techniques (17). Founder animals were identified by Southern blotting and bred to C57/B16 mice.

\section{RNAase Protection}

RNA was purified using the guanidinium-acid phenol method (18). An antisense riboprobe was generated using the Promega Riboprobe kit (Promega, Madison, WI, U.S.A.) and purified by guanidinium-acid phenol extraction followed by isopropanol precipitation. A five hundred thousand-counts per minute probe was combined with $3 \mu \mathrm{g}$ of RNA and hybridized overnight at $55^{\circ} \mathrm{C}$ in $86 \%$ formamide, $2 \mathrm{mM}$ EDTA, $0.433 \mathrm{M} \mathrm{NaCl}, 43 \mathrm{mM}$ Pipes, $\mathrm{pH}$ 6.9. Samples were digested at $37^{\circ} \mathrm{C}$ for $1.5 \mathrm{hr}$ with 40 units of T1 RNAase (Boehringer Mannheim, Indianapolis, IN, U.S.A.) and $0.5 \mu \mathrm{g}$ of RNAase A (Boehringer Mannheim) in $0.5 \mathrm{ml}$ of $0.3 \mathrm{M} \mathrm{NaCl}, 20$ $\mathrm{mM}$ Tris- $\mathrm{HCl}, \mathrm{pH} 7.5,50 \mu \mathrm{g} / \mathrm{ml}$ yeast tRNA. Digestion was stopped by the sequential addition of $10 \mu \mathrm{l} 20 \%$ SDS and $50 \mu \mathrm{l}$ stop buffer (4 M ammonium acetate, $100 \mathrm{mM}$ EDTA, $1 \mathrm{mg} / \mathrm{ml}$ yeast tRNA). The samples were phenol:chloroform-extracted, ethanol-precipitated, and then electrophoresed on a $5 \%$ acrylamide gel under denaturing conditions.

\section{Myofibril Purification and Immunoblotting}

Heart homogenates or myofibrils (19) were electrophoretically separated on 6\% SDS-polyacrylamide gels according to Laemmli (20). Electrophoresis was continued until the Myhs had migrated approximately $8 \mathrm{~cm}$ through a $11-\mathrm{cm}$ separating gel. Immunoblotting was performed as described (21) and chemiluminescent images were quantified using a Molecular Dynamics laser densitometer. The anti- $\alpha$ Myh monoclonal antibody, BAG5 (22), was provided by Dr. S. Schiaffino, Padova, Italy. 


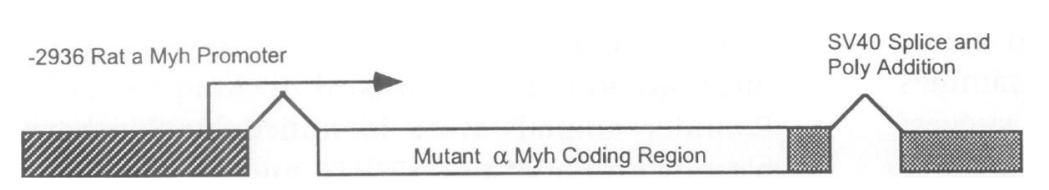

FIG. 1. Establishment of transgenic mouse lines with cardiac-specific expression of a mutant Myh

Transgenic mice were produced in a CBA/B 6 (Fl cross) background and identified using standard techniques. The transgene consists of a mutant rat $\alpha$ Myh cDNA flanked by heterologous introns at the $5^{\prime}$ and $3^{\prime}$ end, and promoter elements provided by approximately $3.3 \mathrm{~kb}$ of rat $\alpha$ Myh 5'-flanking DNA (27). Five independent transgenic lines number were identified: Lines 131, $136,138,140$, and 143 .

\section{Statistical Analysis}

Data were analyzed using an unpaired Student's $t$ test. $p$ values are indicated in the text.

\section{RESULTS}

To test whether the expression of a mutant Myh in the mouse heart results in hypertrophic cardiomyopathy, we created five transgenic mouse lines with cardiac-specific expression of a mutant $\alpha$ Myh. In contrast to humans, where $\beta$ Myh is the predominant cardiac myosin isoform, $\alpha$ Myh is the predominant isoform of the adult mouse ventricle $(23,24)$. Therefore, we used a mutant rat $\alpha$ Myh cDNA to construct the transgene coding region. Rat and mouse $\alpha$ Myh are $98.9 \%$ identical at the amino acid level (22 differences out of 1938 amino acids) with the differences being similar to the neutral polymorphisms found between various inbred mouse strains (25). None of the seven nonconservative differences between rat and mouse $\alpha$ Myh are found in the head or subfragment 1 (S1) region of the Myh, the site of most HCM mutations. The differences are found only in the subfragment 2 (S2; two amino acids) or light meromyosin (LMM; five amino acids) regions. In addition, no HCM mutations have been identified in amino acids that differ between rat and mouse $\alpha$ Myh.

The transgene (Fig. 1) contained both a point mutation (Arg403Gln) and an interstitial deletion ( $\Delta$ aa468-527) in the putative actin binding domain. The combination of these two mutations would be predicted to produce a very strong dominant negative effect by altering the interaction of myosin with actin (26). In addition, the deletion mutation allows the transgene protein to be distinguished electrophoretically from the endogenous mouse Myh. Transgene expression was driven by approximately $3.3 \mathrm{~kb}$ of 5 '-flanking DNA from the rat $\alpha$ Myh gene (27). Five independent transgenic lines were established and cardiac-specific expression of the transgene mRNA was confirmed by ribonuclease (RNase) protection analysis (Fig. 2). Long exposures revealed very low levels of the endogenous mouse $\alpha$ Myh in the lung, as has been previously described (28). However, transgene expression was detected only in the heart. Transgene message was abundant in the hearts of these mice and was found at $26-50 \%$ of the endogenous mouse Myh levels (not shown).

If these transgenic mice are to function as a model for HCM they should exhibit several phenotypic features found in most individuals with the disease $(29,30)$. These include myocyte hypertrophy, myocellular disarray, interstitial fibrosis, and small vessel coronary disease $(2,31)$. Hearts from each transgenic line were examined at 12-14 weeks of age for evidence of these features. In all cases the atria were normal but significant cardiac histopathology was evident in the left ventricle (Fig. 3). In a few animals, some abnormal myocytes were seen in the right ventricle but the vast majority of hypertrophied cells were found in the left ventricle. Foci of myocellular disarray were found throughout the left ventricle accompanied by evidence of increased matrix accumulation (Fig. 3B). When areas with myocellular disarray were identified and then examined at the electron microscope level, several abnormalities were seen (Fig. 4). Degenerating myofibrils, prominent collagen deposits and z-line streaming were apparent. It is interesting to note that severely damaged myocytes often were adjacent to apparently normal cells. In these instances, intact myofibrils were absent near the intercalated discs, implying a lack of force transmission between the adjacent myo- 
FIG. 2. Cardiac-specific transgene expression

Cardiac-specific transgene RNA expression in mouse lines 131 and 140 was determined by ribonuclease (RNase) protection assay. The probe was derived from the $5^{\prime}$ end of the transgene and results in approximately 300 and $200 \mathrm{nt}$ protected fragments for the transgene and the endogenous mouse Myh mRNAs, respectively. Three micrograms of total RNA was assayed and then analyzed on a $5 \%$ denaturing polyacrylamide gel. P, probe; $\mathrm{Tg}$, transgene; Myh, mouse Myh; $\alpha$, rat $\alpha$ Myh; $\mathrm{nH}$, nontransgenic heart; $\mathrm{H}$, heart; $\mathrm{T}$, tongue; Sk, skeletal muscle; $\mathrm{L}$, liver; $\mathrm{S}$, spleen; $\mathrm{K}$, kidney; Lg, lung; $\mathrm{B}$, brain; $\mathrm{U}$, uterus.

cytes. These electron micrographs are virtually indistinguishable from published micrographs of skeletal muscle biopsies from HCM patients $(32,33)$.

Small vessel coronary disease, seen histopathologically as thickening of the medial and intimal layer of small coronary vessels, is found in many patients with HCM (31) and is also present in feline and porcine HCM $(13,14)$. Abnormal coronary vessels were found in the hearts of all transgenic mouse lines (Fig. 3, compare $C$ and $D$ ). Not all vessels were hypertrophied, as evidenced by the presence of normal and abnormal vessels within the same animal. Such vessel-to-vessel heterogeneity is also seen in humans (31). Mutant $\alpha$ Myh expression was not detected in smooth muscle rich tissues such as uterus (Fig. 2) suggesting that it also is not expressed in the smooth muscle layer of the coronary arteries. The smooth muscle hypertrophy seen in small coronary arteries is most likely the result of a compensatory response of the vasculature to dysfunctional cardiac myocytes. While all five lines of mice exhibit histopathology characteristic of the disease, two were relatively mild and three were quite strong in phenotype at the microscopic level. Two transgenic lines (lines 131 and 140) were selected as examples of mild and strong phenotypes, respectively, and retained for further study.

Actin and myosin are normally found in a precise ratio in muscle and alterations in this

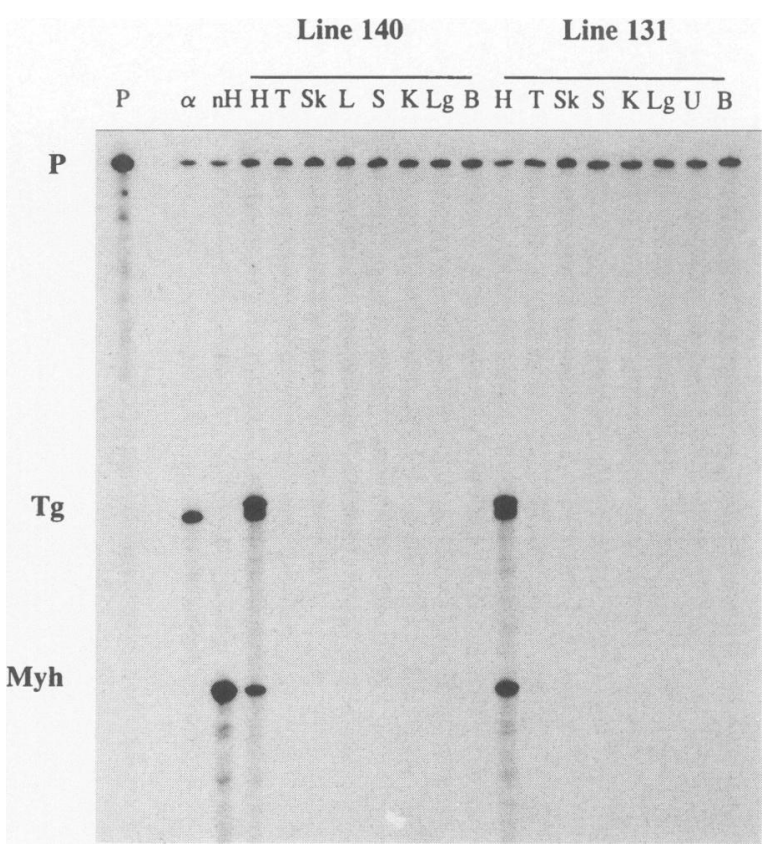

stoichiometry could have profound effects. To determine whether expression of the mutant Myh perturbed contractile protein stoichiometry in these transgenic mice, cardiac myofibrils were prepared from transgenic mice (131 and 140 lines). The ratio of myosin to actin in these preparations was determined by densitometry and compared with control mouse cardiac myofibrils (not shown). The myosin/actin rations were found to be identical, although very small alterations undetectable by our analysis cannot be ruled out. The amount of transgene protein in heart homogenates was determined by SDSacrylamide gel electrophoresis followed by immunoblotting and densitometry. Acrylamide gels were run which optimized the size differences between the mutant and endogenous wild type species. As shown in Fig. 5, the mutant protein comprises $10-12 \%$ of the total myosin in Line 140 and $0.6-2.5 \%$ in Line 131 . Identical results were obtained whether heart homogenates (Fig. 5) or purified myofibrils (not shown) were examined. The low levels of mutant protein, in conjunction with the apparently normal actin/ myosin stoichiometry, suggest that the severe phenotype is due to the dominant effect of the mutant such that a relatively small number of mutant polypeptides exert a "drag" on sarcomere function. Consistent with this conclusion is the report that a mixture of mutant (Arg403Gln) and wild-type myosin exhibits the properties of the 


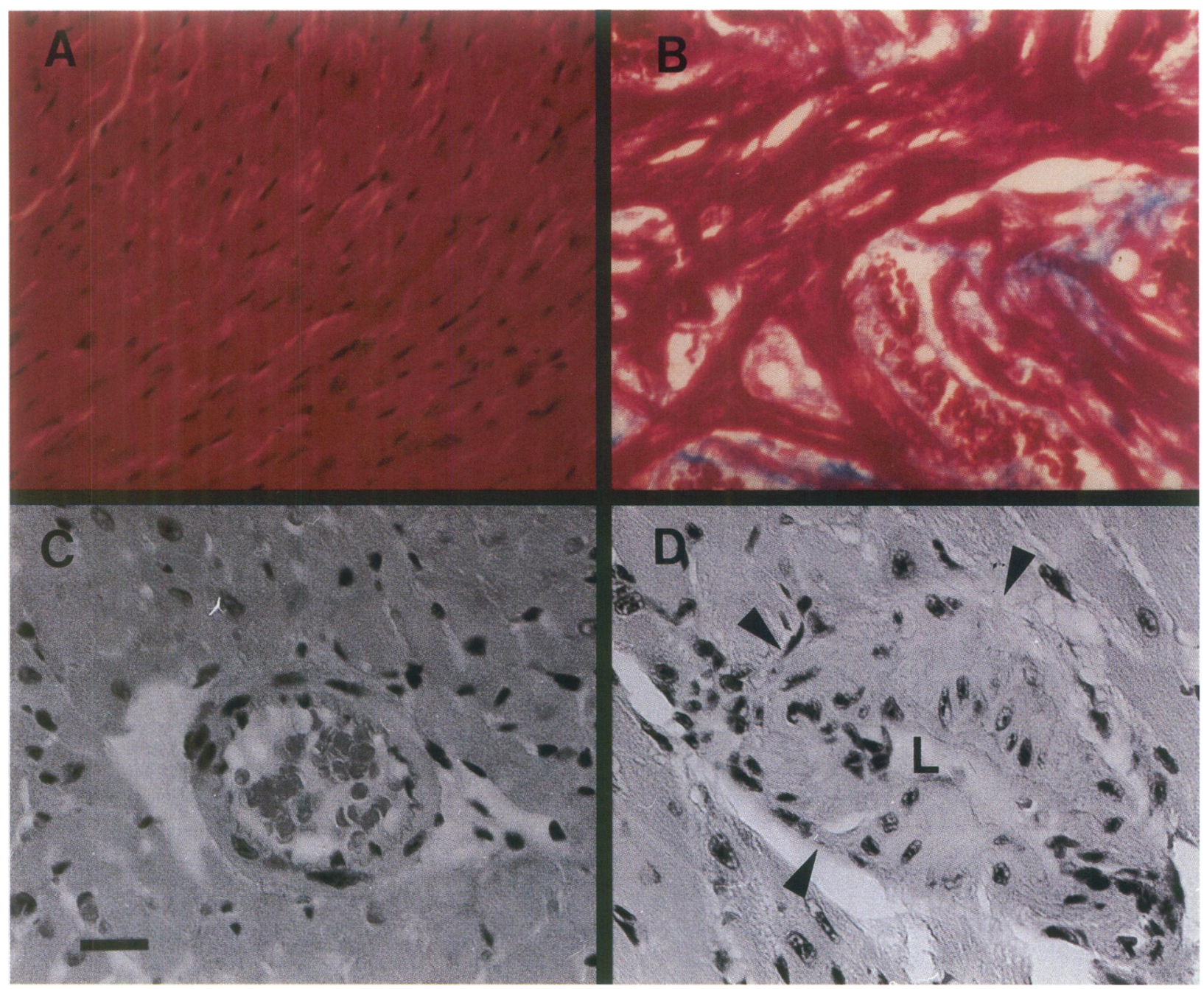

FIG. 3. Transgenic mouse hearts exhibit histopathologic features of $\mathrm{HCM}$

Paraffin sections of hearts from control (A and C) and transgenic (B and D) mice were stained with Masson's trichrome (A and B) or hemotoxylin/eosin (C and D). Evidence of hypertrophic cardiomyopathy was seen in the left ventricle and included focal myocyte hypertrophy and myocellular disarray with increased matrix accumulation. The specimens shown were derived from the 143 (B) and 140 (D) mouse lines.

Many of the transgenic hearts examined also showed evidence of small vessel coronary disease (C and D). Histopathologically, this is seen as a thickening of the smooth muscle layer of the small coronary vessels (see arrows, $\mathrm{D}$; L, lumen). Bar equals $0.1 \mathrm{~mm}(\mathrm{~A}, \mathrm{~B})$ or $0.04 \mathrm{~mm}(\mathrm{C}, \mathrm{D})$.

mutant unless the wild-type constitutes greater than $60 \%$ of the mixture $(10)$.

Atria, left ventricle and right ventricle weights were determined in age-matched transgenic mice ( 12 weeks and 8 months of age) with negative littermates serving as controls (Table 1 and Fig. 6). At 12 weeks of age, the 140 line exhibited significant increases in left and right ventricular mass compared with controls (Table 1; females: LV 12\% $\uparrow$; RV 14\% $\uparrow$; males: LV $7 \% \uparrow, R V 9 \% \uparrow$ ) while no difference in body weight or tibial length was seen. The cardiac hypertrophy in these animals is accompanied by increased message levels of atrial natriuertic factor (ANF) and $\alpha$-skeletal actin (not shown), two molecular markers of cardiac hypertrophy $(34,35)$. Animals from the 131 line did not exhibit significant cardiac hypertrophy at this age. Although large numbers of animals from the other three lines of mice were not examined for heart mass measurements, every transgenic heart from those three lines was hypertrophic by 12 weeks of age. Although the 131 line did exhibit increased levels of ANF and $\alpha$-skeletal actin mRNAs, the levels of these molecular markers of hypertrophy were significantly less than in the 
FIG. 4. The foci of hypertrophy and cellular disarray contain myocytes with degenerating myofibrils

Hearts from 5 month old 140 line transgenic mice were embedded in plastic resin and abnormal regions within the left ventricle were identified in thick sections of plastic embedded tissue. Thin sections were cut from these regions, stained with uranyl acetate and lead citrate and examined on the electron microscope. Myofibrillar disarray as well as degeneration were evident. Most striking was the observation that severely effected myocytes often bordered on apparently normal cells with the frequent loss of myofibrils bordering the intercalated disc. $\mathrm{Bar}=20 \mu \mathrm{m}$.

140 line. By 8 months of age the degree of left ventricular hypertrophy seen in females from the 140 line had more than doubled to $32 \%$. These changes were apparent in the absolute weight of the left ventricles $(12-32 \%)$ or in ventricular weights normalized to tibial length (12$28 \%$ ). In contrast, at 8 months of age the mean heart weight of 140 line males, while still slightly larger than controls, had lost all statistical significance $(p>0.1)$. There is extreme variability in heart and body sizes seen in older male mice (both control and transgenic). However, gross examination of formaldehyde fixed hearts sug-

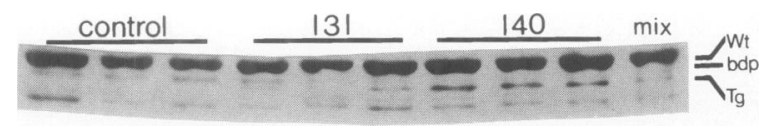

FIG. 5. Mutant Myh protein constitutes a small proportion of the total cardiac myosin

Heart homogenates were prepared from control, 131 line, and 140 line mice, separated on a $6 \%$ acrylamide gel, transferred to nitrocellulose, and probed with an anti- $\alpha$ Myh-specific monoclonal antibody (BAG5 [22]). The position of the wild-type (Wt) and transgene ( $\mathrm{Tg}$ ) proteins are indicated, as well as a closely migrating breakdown product (bdp). The distinct mobilities of the transgene protein and the breakdown product can be seen clearly in the samples from the 131 line as well as in an artificial mixture of control and 140 line homogenates (mix). Laser densitometry indicates that the mutant species comprises less than $12 \%$ of the total myosin $10.6-$ $2.5 \%, 131$ line; $10-12 \%, 140$ line). However, this may be an overestimate due to the impossibility of simultaneously maintaining the wild-type and transgene protein in both the detectable and linear range of the assay. Nevertheless, the data indicate that the relative levels of transgene and endogenous Myh mRNAs do not reflect the levels of mutant protein (Fig. 2).

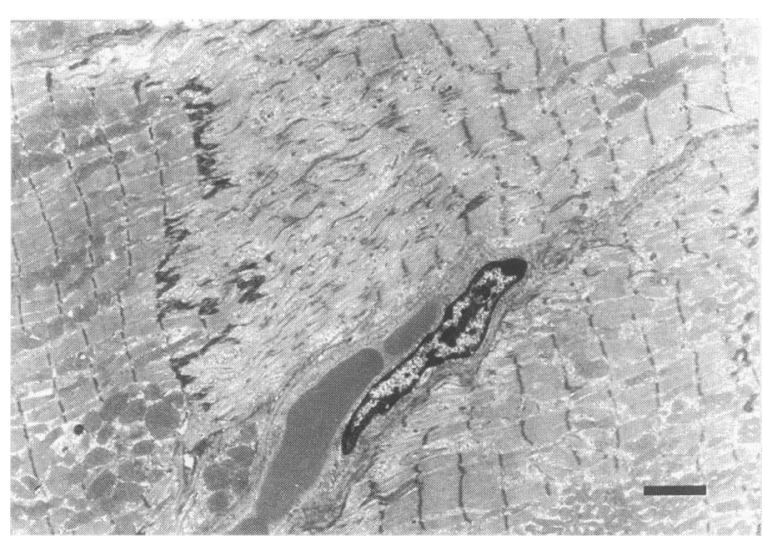

gested that the 140 line hearts had overall dimensions that were much greater than the controls (Fig. 7, A and B). This group exhibited significant chamber dilation (Fig. 7). In control hearts the left ventricular cavity was a normal crescent shape (seven out of seven hearts examined) while in all 8-month 140 line males (five hearts examined) the left ventricular cavity was dilated and almond-shaped (Fig. 6).

\section{DISCUSSION}

Molecular genetic analysis has revealed that hypertrophic cardiomyopathy is often associated with mutations in genes encoding contractile proteins. This has led to the hypothesis that HCM is a disease of the sarcomere (5). However, the exact relationship between mutant contractile proteins and the phenotype remains unclear. Characterizing HCM pathogenesis at a cellular and molecular level may provide the information needed to address this question. We have created five independent transgenic mouse lines with cardiac-specific expression of a mutant Myh. Like human HCM, the animal model shows left ventricular hypertrophy, myocyte hypertrophy, myocellular disarray, fibrosis, and small vessel coronary disease. Based on these findings, the transgenic mice are a good model for HCM and their analysis provides insight into the mechanisms involved in developing the disease phenotype.

It is clear that mutant contractile proteins are the initial insult in the development of HCM, but patients do not die purely as the result of sarcomeric dysfunction. We suspect that mutations in $\beta$ Myh, cardiac troponin T, $\alpha$-tropomyosin, and cardiac myosin binding protein $C$ trigger a patho- 
TABLE 1. Cardiac hypertrophy in HCM mice ${ }^{a}$

\begin{tabular}{|c|c|c|c|c|c|c|}
\hline & Heart (mg) & Atria (mg) & RV (mg) & LV (mg) & Body (g) & $\begin{array}{c}\text { Tibial Length } \\
\text { (mm) }\end{array}$ \\
\hline \multicolumn{7}{|l|}{$\begin{array}{l}\text { A. Heart and } \\
\text { Chamber } \\
\text { Weights, } \\
\text { Female Mice }\end{array}$} \\
\hline \multicolumn{7}{|l|}{12 weeks } \\
\hline $\begin{array}{l}\text { Control } \\
\quad(n=16)\end{array}$ & $99.6 \pm 4.4$ & $5.2 \pm 0.6$ & $19.1 \pm 1.4$ & $68.8 \pm 3.7$ & $22.2 \pm 1.3$ & $16.9 \pm 0.2$ \\
\hline $\begin{array}{l}131 \text { line } \\
\quad(n=8)\end{array}$ & $94.3 \pm 5.8^{a}$ & $4.3 \pm 1.0^{a}$ & $18.5 \pm 1.0^{a}$ & $65.0 \pm 5.3^{a}$ & $21.1 \pm 1.0^{a}$ & $16.8 \pm 0.3$ \\
\hline $\begin{array}{l}140 \text { line } \\
(n=9)\end{array}$ & $114.4 \pm 12.4^{a}$ & $5.2 \pm 0.6$ & $21.8 \pm 2.1^{b}$ & $76.9 \pm 8.7^{b}$ & $22.0 \pm 1.1$ & $16.7 \pm 0.4$ \\
\hline \multicolumn{7}{|l|}{8 months } \\
\hline $\begin{array}{l}\text { Control } \\
\quad(n=8)\end{array}$ & $96.6 \pm 2.9$ & $4.5 \pm 0.7$ & $17.5 \pm 1.3$ & $66.8 \pm 3.9$ & $22.6 \pm 2.1$ & $17.3 \pm 0.4$ \\
\hline $\begin{array}{l}131 \text { line } \\
\quad(n=10)\end{array}$ & $104.4 \pm 10.9^{a}$ & $4.8 \pm 1.1$ & $17.6 \pm 2.0$ & $73.0 \pm 8.7$ & $24.9 \pm 2.7$ & $18.1 \pm 0.8^{a}$ \\
\hline $\begin{array}{l}140 \text { line } \\
\quad(n=16)\end{array}$ & $125.8 \pm 14.9^{b}$ & $5.2 \pm 1.0$ & $23.3 \pm 3.5^{b}$ & $88.4 \pm 9.8^{b}$ & $28.0 \pm 3.0^{b}$ & $17.7 \pm 0.4^{a}$ \\
\hline \multicolumn{7}{|l|}{$\begin{array}{l}\text { B. Heart and } \\
\text { Chamber } \\
\text { Weights, } \\
\text { Male Mice }\end{array}$} \\
\hline \multicolumn{7}{|l|}{12 weeks } \\
\hline $\begin{array}{l}\text { Control } \\
\qquad(n=13)\end{array}$ & $111.0 \pm 5.5$ & $5.8 \pm 0.6$ & $22.1 \pm 1.6$ & $74.7 \pm 4.2$ & $26.2 \pm 1.0$ & $17.2 \pm 0.3$ \\
\hline $\begin{array}{l}131 \text { line } \\
\quad(n=9)\end{array}$ & $109.5 \pm 5.7$ & $5.0 \pm 0.8^{a}$ & $21.8 \pm 2.3$ & $74.1 \pm 3.2$ & $25.6 \pm 1.9$ & $16.9 \pm 0.2$ \\
\hline $\begin{array}{l}140 \text { line } \\
\quad(n=7)\end{array}$ & $119.0 \pm 6.7^{a}$ & $5.9 \pm 1.3$ & $24.1 \pm 1.8^{a}$ & $79.8 \pm 4.6^{a}$ & $25.6 \pm 1.5$ & $17.0 \pm 0.2$ \\
\hline \multicolumn{7}{|l|}{8 months } \\
\hline $\begin{array}{l}\text { Control } \\
\quad(n=7)\end{array}$ & $153.8 \pm 26.9$ & $7.6 \pm 2.6$ & $27.4 \pm 5.9$ & $107.3 \pm 19.0$ & $33.2 \pm 4.9$ & $17.8 \pm 0.3$ \\
\hline $\begin{array}{l}131 \text { line } \\
\quad(n=8)\end{array}$ & $138.1 \pm 16.8$ & $6.4 \pm 1.0$ & $24.5 \pm 3.6$ & $98.6 \pm 14.0$ & $31.2 \pm 3.8$ & $17.7 \pm 0.2$ \\
\hline $\begin{array}{l}140 \text { line } \\
\quad(n=7)\end{array}$ & $161.4 \pm 15.4$ & $7.2 \pm 2.1$ & $27.4 \pm 3.3$ & $116.0 \pm 11.9$ & $33.5 \pm 3.9$ & $17.5 \pm 0.3$ \\
\hline $\begin{array}{l}{ }^{a} \text { Values } \pm \text { SD } \\
{ }^{b} p<0.05 \\
c_{p}<0.005\end{array}$ & & & & & & \\
\hline
\end{tabular}

genic pathway resulting in a common phenotype, hypertrophic cardiomyopathy. The analysis of murine HCM presented here suggests that the appearance of histologic abnormalities may be one of the "triggering" events in the development of HCM. Mice from both the 131 and 140 lines exhibit cardiac histopathology, while in- creased cardiac mass is seen only in the 140 line, suggesting that the appearance of histologic abnormalities precedes the development of hypertrophy. Similar examples of HCM without chamber hypertrophy have been reported in the patient population (36). The ultrastructural abnormalities seen in these transgenic mice suggest 


\section{LEFT VENTRICULAR HYPERTROPHY AS A FUNCTION OF AGE AND SEX}

FIG. 6. Progressive cardiac hypertrophy is seen only in female transgenic mice

Left ventricle weights were determined for age-matched transgenic mice and their negative littermates and normalized to tibial lengths.
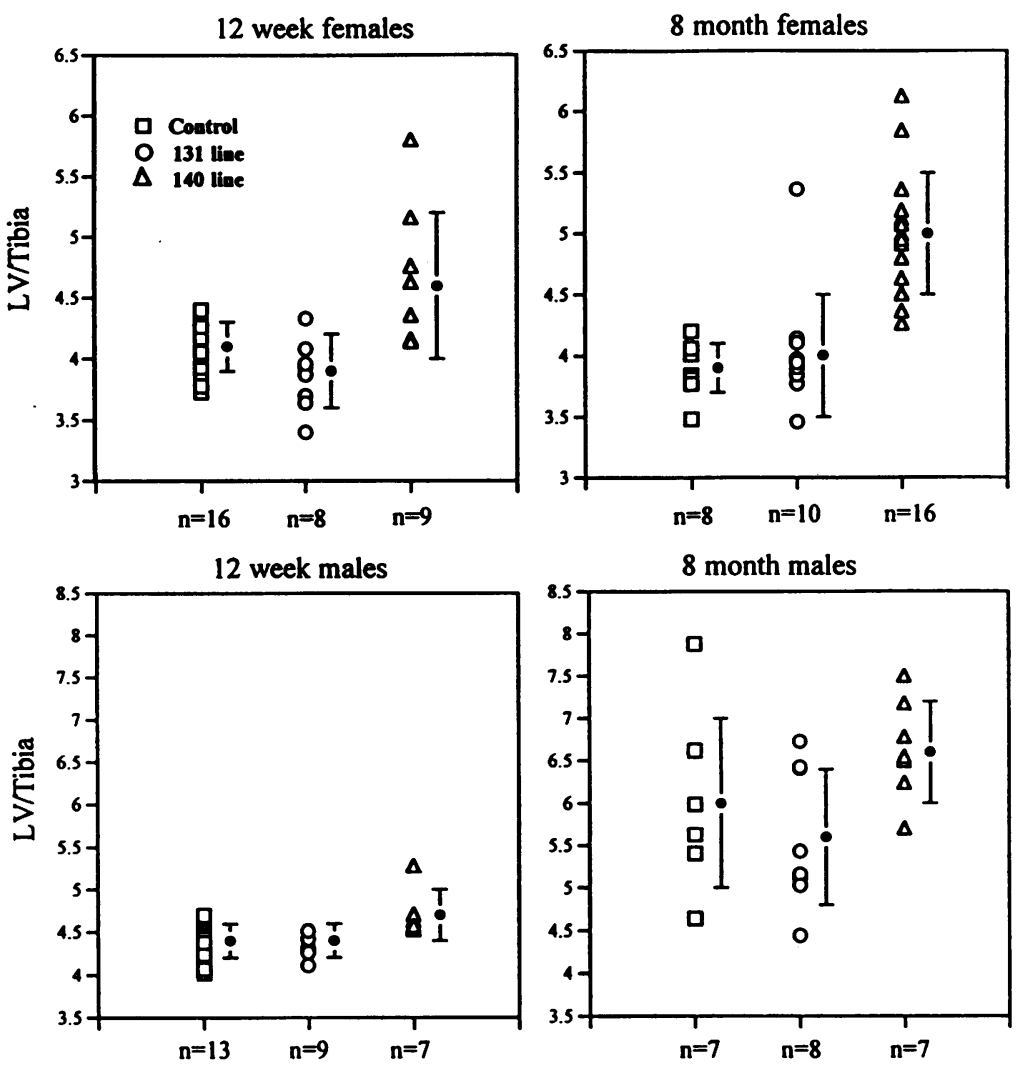

a possible mechanism for the triggering event. The degeneration of myofibrils at the site of their attachment to the intercalated disk (Fig. 4) would result in a myocyte unable to transmit force to its neighbor. This "gap" in the forceproducing machinery could then trigger compensatory responses in the tissue, such as reorientation of the surrounding myocytes (disarray) and hypertrophy. Thus, expression of low levels of a strongly dominant negative mutant protein (such as seen in these transgenic mice) could trigger profound effects in the heart. Further work to establish the precise order in which the features of hypertrophic cardiomyopathy appear in these mice can test this hypothesis.

We suggest that there exists a threshold of sarcomeric dysfunction which, when surpassed, triggers a greater hypertrophic response. The nature of the mutant protein, the work load imposed upon the muscle as well as the amount of the mutant protein may all determine when this threshold is reached. Thus, individuals with two copies of a fairly benign mutation would be pre- dicted to exhibit a more severe phenotype than family members with only one copy of the mutant gene, as has been reported (37). In addition, mouse lines with greater (140 line) or lesser (131 line) expression of a mutant Myh would be predicted to exhibit stronger or milder phenotypes, respectively, as our data show.

Since transgenic mice are an excellent tool for analyzing phenotypic changes over time, it was interesting to note that in the 140 line older male and female mice exhibit distinct phenotypes. While the cardiac hypertrophy was increased in older female animals, male 140 line mice exhibited significant dilation of the left ventricle (Fig. 7). Although sex-specific differences in the HCM phenotype have not been reported in humans, clinical heterogeneity is a hallmark of this disease. In addition, HCM patients often exhibit progressive wall thinning or relative ventricular dilation as they age $(38-41)$. The development of ventricular dilation resulting in endstage heart failure has also been reported in families where the primary end result of the 

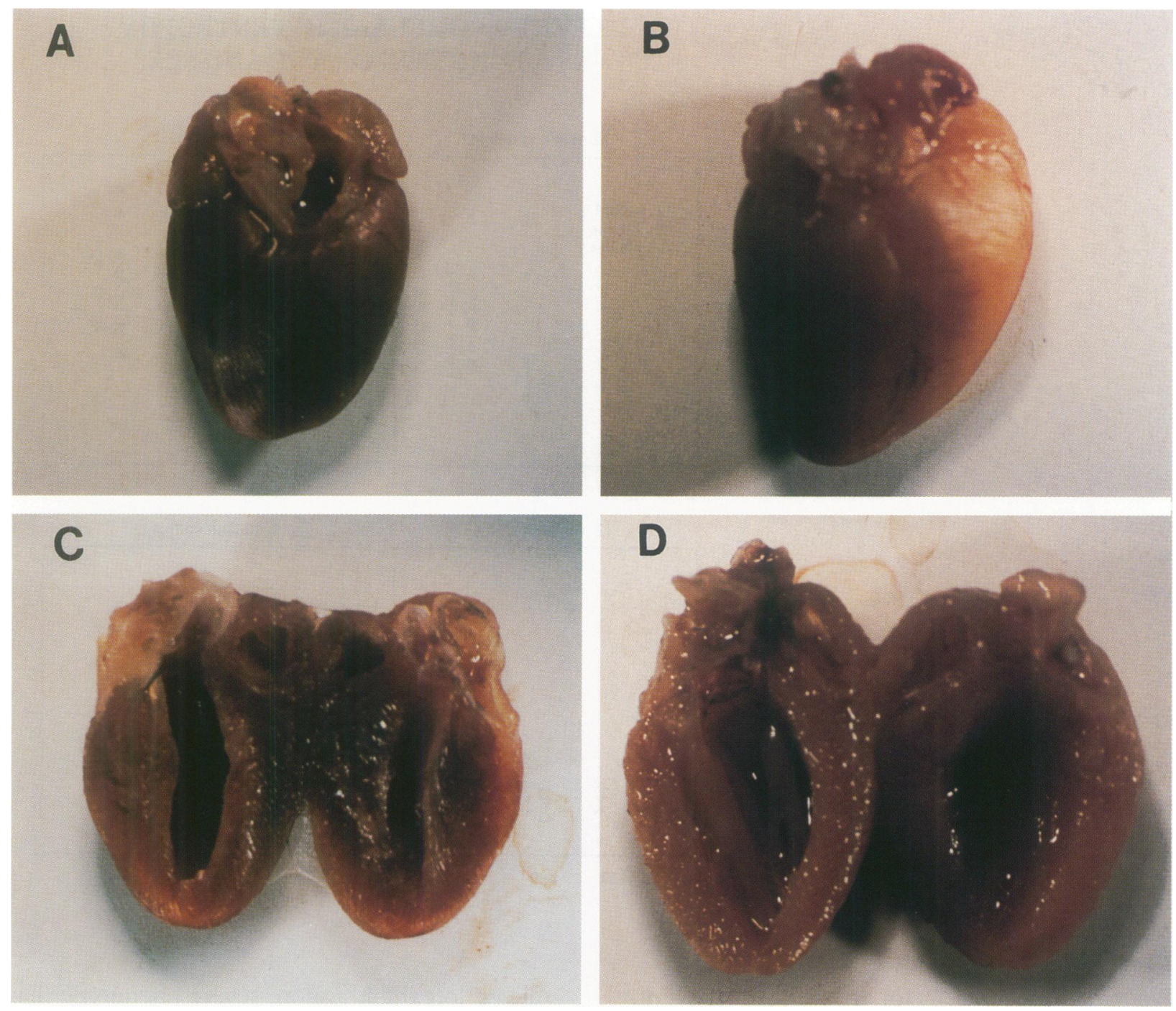

FIG. 7. Chamber dilatation in 8 month old male transgenic mice

Formaldehyde fixed hearts, both control (A and C) and 140 line transgenic (B and D), were bisected axially by an incision through the anterior face of the left ventricle. The two halves of the heart were splayed open to reveal the left ventricular cavity (C and D). In this position, the atria are hidden behind the two halves of the heart, the left ventricular free wall is distal and the right ventricular free wall is medial to the vertical axis.

disease is cardiac sudden death (41). The development of sex-specific phenotypes in the 140 line animals may provide a fortuitous tool for deciphering the factors contributing to the clinical course of the disease as well as the molecular mechanisms leading to dilated cardiomyopathy.

Although cardiac disease in a small mammal is inherently different from that seen in humans, the mouse allows analyses of disease at molecular and cellular levels impossible in humans. Mouse models of cardiac hypertrophy, such as those resulting from overexpression of protooncogenes $(42,43)$ or calmodulin $(44)$ in the heart demonstrate some similarities to the hy- pertrophy in the transgenic animals described in this report. However, the hypertrophic stimulus in those animals is quite different from that in the HCM mice. In addition, while one recently described mouse model for HCM (15) genetically most closely resembles the human disease, phenotypically it displays substantial difference, namely profound left atrial enlargement in the absence of ventricular hypertrophy. The difference in phenotype may be due to the nature of the mutation, the genetic background, or both. Nevertheless, insight into the basic mechanisms underlying cardiac hypertrophy may be gained from comparing the different models. In addi- 
tion, the knowledge gained from studying cardiac pathogenesis in the HCM mice should impact our knowledge of human HCM. The power of using a combined molecular and morphological analysis of these transgenic mice and the ability to breed them with other genetically altered mouse lines should facilitate the search for the elements involved in the pathogenesis of HCM and the identification of potential therapeutic targets.

\section{ACKNOWLEDGMENTS}

This work has been supported by a grant-in-aid from the New York Heart Association and the receipt of a National Institutes of Health (NIH) merit award (LAL). KLV was supported by the Sammy Davis, Jr., Neuromuscular Disease PostDoctoral Fellowship from the Muscular Dystrophy Association and subsequently by a NIH training grant (PHS5T32HL07271). The authors would like to thank Dr. Glenn Fishman for assembling the full-length $\alpha$ Myh cDNA and Dr. Tom Harris for his instruction in producing transgenic mice. The authors also thank Dr. Doug Robertson for his advice on statistical analysis.

\section{REFERENCES}

1. Maron BJ, Bonow RO, Cannon RO, Leon MB, Epstein SE. (1987) Hypertrophic cardiomyopathy. Interrelations of clinical manifestations, pathophysiology, and therapy. Part one. N. Engl. J. Med. 316: 780-789.

2. Geisterfer-Lowrance AAT, Kass S, Tanigawa $G$, et al. (1990) A molecular basis for familial hypertrophic cardiomyopathy. A $\beta$ cardiac myosin heavy chain gene missense mutation. Cell 62: 999-1006.

3. Tanigawa G, Jarcho JA, Kass S, et al. (1990) Molecular basis for familial hypertrophic cardiomyopathy: A $\alpha / \beta$ cardiac myosin hybrid gene. Cell 62: 991-998.

4. Vikstrom KL, Leinwand LA. (1996) Contractile protein mutations and heart disease. Curr. Opin. Cell Biol. 8: 97-105.

5. Thierfelder L, Watkins $\mathrm{H}$, MacRae $\mathrm{C}$, et al. (1994) $\alpha$-Tropomyosin and cardiac troponin t mutations cause familial hypertrophic cardiomyopathy: A disease of the sarcomere. Cell 77: 701-712.

6. Watkins H, McKenna WJ, Thierfelder L, et al. (1995) Mutations in the genes for cardiac troponin $\mathrm{t}$ and $\alpha$-tropomyosin in hypertrophic cardiomyopathy. N. Engl. J. Med. 332: 1058-1064.

7. Bonne G, Carrier L, Bercovici J, et al. (1995) Cardiac myosin binding protein- $\mathrm{C}$ gene splice acceptor site mutation is associated with familial hypertrophic cardiomyopathy. Nature Genet. 11: 438-440.

8. Watkins $\mathrm{H}$, Conner $\mathrm{D}$, Thierfelder L, et al. (1995) Mutations in the cardiac myosin binding protein- $\mathrm{C}$ gene on chromosome 11 cause familial hypertrophic cardiomyopathy. Nature Genet. 11: 434-437.

9. Cuda G, Fananapazir L, Zhu W, Sellers JR, Epstein ND. (1993) Skeletal muscle expression and abnormal function of $\beta$-myosin in hypertrophic cardiomyopathy. J. Clin. Invest. 91: 2861-2865.

10. Sweeney HL, Straceski AJ, Leinwand LA, Faust L. (1994) Heterologous expression of a cardiomyopathic myosin that is defective in its actin interaction. J. Biol. Chem. 269: 16031605.

11. Ko Y, Tang T, Chen J, Hshieh Y, Wu C, Lien W. (1992) Idiopathic hypertrophic cardiomyopathy in identical twins. Morphological heterogeneity of the left ventricle. Chest 102: 783-785.

12. Fananapazir L, Epstein ND. (1994) Genotype-phenotype correlations in hypertrophic cardiomyopathy. Insights provided by comparisons of kindreds with distinct and identical $\beta$-myosin heavy chain gene mutations. Circulation 89: 22-32.

13. Liu S, Roberts WC, Maron BJ. (1993) Comparison of morphologic findings in spontaneously occurring hypertrophic cardiomyopathy in humans, cats and dogs. Am. J. Cardiol. 72: 944-951.

14. Liu S, Chiu YT, Shyu JJ, et al. (1994) Hypertrophic cardiomyopathy in pigs: Quantitative pathologic features in 55 cases. Cardiovasc. Pathol. 3: 261-268.

15. Geisterfer-Lowrance AAT, Christe M, Conner DA, et al. (1996) A mouse model of familial hypertrophic cardiomyopathy. Science 272: 731-734.

16. McNally EM, Gianola KM, Leinwand LA. (1989) Complete nucleotide sequence of full length cDNA for rat $\alpha$ myosin heavy chain. Nuclic Acids Res. 17: 7527-7528.

17. Hogan B, Constantini F, Lacy E. (1986) Manipulating the Mouse Embryo. A Laboratory Manual. Cold Spring Harbor Press, Cold Spring Harbor, NY. 
18. Chomczynski P, Sacchi N. (1987) Single-step method of RNA isolation by acid guanidinium thiocyanate-phenol-chloroform extraction. Anal. Biochem. 162: 156-169.

19. Solaro RJ, Pang DC, Briggs N. (1971) The purification of cardiac myofibrils with triton X-100. Biochim. Biophys. Acta 245: 259-262.

20. Laemmli UK. (1970) Cleavage of structural proteins during the assembly of the head of bacteriophage T4. Nature 227: 680-685.

21. Vikstrom KL, Rovner AS, Bravo-Zehnder M, Saez CG, Straceski AJ, Leinwand LA. (1993) Sarcomeric myosin heavy chain expressed in nonmuscle cells forms thick filaments in the presence of substoichiometric amounts of light chains. Cell Motil. Cytoskeleton 26: 192204.

22. Rudnicki MA, Jackowski G, Saggin L, McBurney MW. (1990) Actin and myosin expression during development of cardiac muscle from cultured embryonal carcinoma cells. Dev. Biol. 138: 348-358.

23. Lyons GE, Schiaffino S, Sassoon D, Barton $P$, Buckingham M. (1990) Developmental regulation of myosin gene expression in mouse cardiac muscle. J. Cell Biol. 111: 2427-3436.

24. Ng WA, Grupp IL, Subramaniam A, Robbins J. (1991) Cardiac myosin heavy chain mRNA expression and myocardial function in the mouse heart. Circ. Res. 68: 1742-1750.

25. Quinn-Laquer BK, Kennedy JE, Wei SJ, Beisel KW. (1992) Characterization of the allelic differences in the mouse cardiac $\alpha$-myosin heavy chain coding sequence. Genomics 13: 176-188.

26. Rayment I, Holden HM, Whittaker M, et al. (1993) Structure of the actin-myosin complex and its implications for muscle contraction. Science 261: 58-65.

27. Gustafson TA, Bahl JJ, Markham BE, Roeske WR, Morkin E. (1987) Hormonal regulation of myosin heavy chain and alpha actin gene expression in cultured fetal rat heart myocytes. J. Biol. Chem. 262: 13316-13322.

28. Subramaniam A, Jones WK, Gulick J, Wert S, Neumann J, Robbins J. (1991) Tissuespecific regulation of the $\alpha$-myosin heavy chain gene promoter in transgenic mice. J. Biol. Chem. 266: 24613-24620.

29. Becker AE, Caruso G. (1982) Myocardial disarray. A critical review. Br. Heart J. 47: 527538.

30. Wenger NK, Abelmann MH, Roberts WC. (1990) Cardiomyopathy and specific heart muscle disease. In: Hurst JW, Schlant RC,
Rackley CE, Sonnenblick EH, Wenger NK (eds). The Heart, Arteries and Veins. 7th ed. MacGraw-Hill, New York. Vol. 65, pp. 12781374.

31. Maron BJ, Wolfson JK, Epstein SE, Roberts WC. (1986) Intramural ("small vessel") coronary artery disease in hypertrophic cardiomyopathy. J. Am. Coll. Cardiol. 8: 545-557.

32. Smith ER, Heffernan LP, Sangalang VE, Vaughan LM, Flemington CS. (1976) Voluntary muscle involvement in hypertrophic cardiomyopathy. A study of eleven patients. Ann. Intern. Med. 85: 566-572.

33. Fananapazir L, Dalakas MC, Cyran F, Cohn G, Epstein ND. (1993) Missense mutations in the $\beta$-myosin heavy-chain gene cause central core disease in hypertrophic cardiomyopathy. Proc. Natl. Acad. Sci. U.S.A. 90: 39933997.

34. Schwartz $K$, de la Bastie $D$, Bouveret $P$, Oliviero P, Alonso S, Buckingham M. (1986) $\alpha$-Skeletal muscle actin mRNA's accumulate in hypertrophied adult rat hearts. Circ. Res. 59: 551-555.

35. Boheler KR, Carrier L, de la Bastie D, et al. (1991) Skeletal actin mRNA increases in the human heart during ontogenic development and is the major isoform of control and failing human hearts. J. Clin. Invest. 88: 323330.

36. McKenna WJ, Stewart JT, Nihoyannapoulos P, McGinty F, Davies MJ. (1990) Hypertrophic cardiomyopathy without the hypertrophy: Two families with myocardial disarray in the absence of increased myocardial mass. Br. Heart. J. 63: 287-290.

37. Nishi H, Kimura A, Adachi K, Koga Y, Sasazuki T, Toshima H. (1994) Possible gene dose effect of a mutant cardiac $\beta$-myosin heavy chain on the clinical expression of familial hypertrophic cardiomyopathy. Biochem. Biophys. Res. Commun. 200: 549-556.

38. ten Cate FG, Roelandt J. (1979) Progression to left ventricular dilatation in patients with hypertrophic cardiomyopathy. Am. Heart J. 97: 762-765.

39. Fujiwara H, Onoder T, Tanaka M. (1984) Progression from hypertrophic obstructive cardiomyopathy to typical dilated cardiomyopathy. Jpn. Circ. J. 48: 1210-1214.

40. Spirito P, Maron BJ, Bonow RO, Epstein SE. (1987) Occurrence and significance of progressive left ventricular wall thinning and relative cavity dilatation in hypertrophic cardiomyopathy. Am. J. Cardiol. 59: 123-129. 
41. Hecht GM, Klues HG, Roberts WC, Maron BJ. (1993) Coexistence of sudden cardiac death and end-stage heart failure in familial hypertrophic cardiomyopathy. J. Am. Coll. Cardiol. 22: 489-497.

42. Jackson T, Allard MF, Sreenan CM, Doss LK, Bishop SP, Swain JL. (1991) Transgenic animals as a tool for studying the effect of the c-myc proto-oncogene on cardiac development. Mol. Cell. Biochem. 104: 15-19.

43. Hunter JJ, Tanaka N, Rockman HA, Ross Jr
J, Chien KR. (1996) Ventricular expression of a MLC-2v-ras fusion gene induces cardiac hypertrophy and selective diastolic dysfunction in transgenic mice. J. Biol. Chem. 270: 23173-23178.

44. Gruver CL, DeMayo F, Goldstein MA, Means AR. (1993) Targeted developmental overexpression of calmodulin induces proliferative and hypertrophic growth of cardiomyocytes in transgenic mice. Endocrinology 133: 376388.

Contributed by J. M. Leiden on July 3, 1996. 